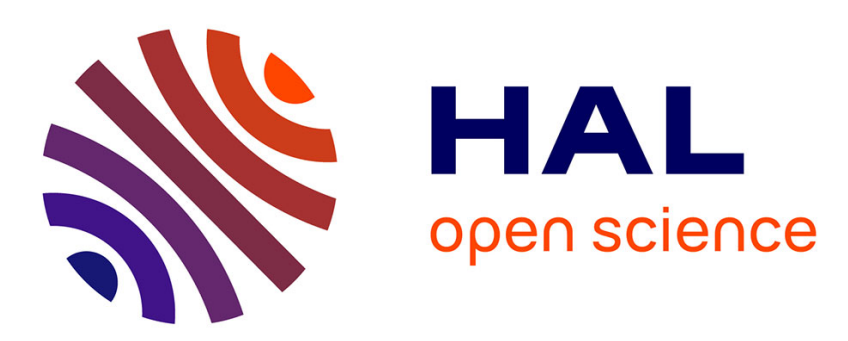

\title{
Effect of an intervention on the features of adverse drug reactions spontaneously reported in a hospital
}

Gloria Cereza, Antonia Agustí, Consuelo Pedrós, Antonio Vallano, Cristina

Aguilera, Immaculada Danés, Xavier Vidal, Josep Maria Arnau

\section{- To cite this version:}

Gloria Cereza, Antonia Agustí, Consuelo Pedrós, Antonio Vallano, Cristina Aguilera, et al.. Effect of an intervention on the features of adverse drug reactions spontaneously reported in a hospital. European Journal of Clinical Pharmacology, 2010, 66 (9), pp.937-945. 10.1007/s00228-010-0856-8 . hal-00600755

\section{HAL Id: hal-00600755 \\ https://hal.science/hal-00600755}

Submitted on 16 Jun 2011

HAL is a multi-disciplinary open access archive for the deposit and dissemination of scientific research documents, whether they are published or not. The documents may come from teaching and research institutions in France or abroad, or from public or private research centers.
L'archive ouverte pluridisciplinaire HAL, est destinée au dépôt et à la diffusion de documents scientifiques de niveau recherche, publiés ou non, émanant des établissements d'enseignement et de recherche français ou étrangers, des laboratoires publics ou privés. 


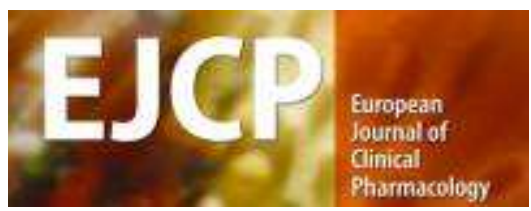

\section{EFFECT OF AN INTERVENTION ON THE FEATURES OF ADVERSE DRUG REACTIONS SPONTANEOUSLY REPORTED IN A HOSPITAL}

\begin{tabular}{|c|c|}
\hline Journal: & European Journal of Clinical Pharmacology \\
\hline Manuscript ID: & EJCP-2010-0043.R2 \\
\hline Type of submission: & Original \\
\hline $\begin{array}{r}\text { Date Submitted by the } \\
\text { Author: }\end{array}$ & 17-May-2010 \\
\hline Complete List of Authors: & $\begin{array}{l}\text { Cereza, Gloria; Fundació Institut Català de Farmacologia, } \\
\text { Pharmacovigilance; Catalan Centre of Pharmacovigilance, } \\
\text { Pharmacovigilance } \\
\text { Agustí, Antonia; Fundació Institut Català de Farmacologia, Clinical } \\
\text { Pharmacology; Hospital Vall D'Hebron, Clinical Pharmacology } \\
\text { Service; Universitat Autònoma de Barcelona, Department of } \\
\text { Pharmacology, Therapeutics and Toxicology } \\
\text { Pedrós, Consuelo; Hospital de Bellvitge, Clinical Pharmacology } \\
\text { Service } \\
\text { Vallano, Antonio; Hospital de Bellvitge, Clinical Pharmacology } \\
\text { Service; Universitat de Barcelona, Department of Pathology and } \\
\text { Experimental Therapeutics } \\
\text { Aguilera, Cristina; Fundació Institut Català de Farmacologia, Clinical } \\
\text { Pharmacology; Hospital Vall D'Hebron, Clinical Pharmacology } \\
\text { Service } \\
\text { Danés, Immaculada; Fundació Institut Català de Farmacologia, } \\
\text { Clinical Pharmacology; Hospital Vall D'Hebron, Clinical } \\
\text { Pharmacology Service; Universitat Autònoma de Barcelona, } \\
\text { Department of Pharmacology, Therapeutics and Toxicology } \\
\text { Vidal, Xavier; Fundació Institut Català de Farmacologia, Clinical } \\
\text { Pharmacology; Hospital Vall D'Hebron, Clinical Pharmacology } \\
\text { Service; Universitat Autònoma de Barcelona, Department of } \\
\text { Pharmacology, Therapeutics and Toxicology } \\
\text { Arnau, Josep Maria; Hospital de Bellvitge, Clinical Pharmacology } \\
\text { Service; Universitat de Barcelona, Department of Pathology and } \\
\text { Experimental Therapeutics }\end{array}$ \\
\hline
\end{tabular}




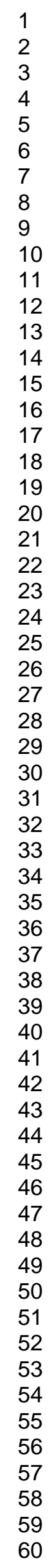

2

4

5

7

8

10

11

12

13

14

16

17

18

19

20

22

24

26

27

29

30

33

34

35

36

39

40

41

43

44

45

46

47

48

49

50

52

53

54

56

57

58

59

60 


\section{EFFECT OF AN INTERVENTION ON THE FEATURES OF ADVERSE DRUG REACTIONS SPONTANEOUSLY REPORTED IN A HOSPITAL}

Cereza $G^{1,2}$, Agustí $A^{1,3,4}$, Pedrós $C^{5}$, Vallano $A^{5,6}$, Aguilera $C^{1,3}$, Danés $I^{1,3,4}$, Vidal $\mathrm{X}^{1,3,4}$, Arnau $\mathrm{JM}^{5,6}$

${ }^{1}$ Fundació Institut Català de Farmacologia, Barcelona, Spain

${ }^{2}$ Catalan Centre of Pharmacovigilance, Barcelona, Spain

${ }^{3}$ Clinical Pharmacology Service, Hospital Universtari Vall d'Hebron, Barcelona, Spain

${ }^{4}$ Department of Pharmacology, Therapeutics, and Toxicology, Universitat Autònoma de Barcelona, Barcelona, Spain

${ }^{5}$ Clinical Pharmacology Service, Hospital Universitari de Bellvitge, Hospitalet de Llobregat, Spain

${ }^{6}$ Department of Pathology and Experimental Therapeutics, Universitat de Barcelona, Spain

Words account 3,579

Correspondence: Dr. Gloria Cereza

Fundació Institut Català de Farmacologia

Passeig Vall d'Hebron 119-129

08035 - Barcelona, Spain

E-mail: gcg@icf.uab.cat 


\section{ABSTRACT}

Background.- A continuous intervention based on healthcare management agreements was associated in our hospital with an increase in the absolute number of spontaneous reporting of adverse drug reactions (ADRs), and also with an increase in the number of reports of serious or unexpected ADRs and ADRs associated with new drugs.

Objective.- To analyze the effect of this intervention on the features of ADRs spontaneously reported in a hospital, the drugs involved and the number of signals identified.

Methods.- A longitudinal study with two periods, the $1^{\text {st }}$ period without intervention from 1998 to 2002 and the $2^{\text {nd }}$ period with intervention from 2003 to 2005 , was carried out in a teaching tertiary Hospital. Changes between the two periods in the following variables were analysed: (a) the patients' characteristics, such as gender and age; (b) the reported ADRs, and their medical assistance required; (c) the suspected drugs involved in the ADRs and (d) the main signals identified.

Results.- Gender and age distribution of patients described in the spontaneous reports were no different in the two periods. During the second period, spontaneously reported cases requiring hospital admission and those occurring in-hospital increased (236 from 2 in the first period and 277 from 99 in the first period, respectively) and cases from outpatient hospital consultations began to be reported (13.9\% of reports). The spontaneous reporting on all kinds of ADRs and drugs increased during the second period. Cutaneous reactions were the most frequently spontaneous reported ADRs in both periods followed by cardiovascular and neurological reactions in the first period, and haematological and gastrointestinal reactions in the second one. However, during the second period the higher increase was for endocrinological, urinary and hepatic reactions. Systemic antibiotics, antithrombotics and cardiac therapy drugs were the most commonly therapeutic subgroups reported as suspected drugs in both periods, but in the second period the proportion of immunostimulants, beta blocking agents, immunosuppressants and psychoanaleptics increased. No 
signals were recognized during the first period, however two signals and one additional safety concern were identified during the second.

Conclusion.- An intervention based on healthcare management agreements, was associated with an important increase in spontaneous reporting of ADRs by hospital physicians and also with a change in terms of type of ADRs identified affecting different organs or systems, and the therapeutic groups of drugs involved. Future studies should analyze the effect of different types of intervention on spontaneous reporting of ADRs in hospitals.

Words account: 399

Keywords: Pharmacovigilance; Adverse Drug Reactions Reporting Systems;

Drug Toxicity; Intervention Studies; Hospital 


\section{INTRODUCTION}

The spontaneous reporting system is currently the cornerstone of postmarketing signal detection in pharmacovigilance. ${ }^{[1-2]}$ Detection of adverse drug reactions (ADRs) in hospitals is important because serious events may be identified, novel drugs are commonly used, new and unexpected ADRs may be detected early on and cases are usually well-documented with high quality information. Nevertheless, spontaneous reporting has been scarcely used as a method of ADRs detection in hospitals and underreporting is a major flaw, ${ }^{[3-5]}$ as it is in the primary health care setting. ${ }^{[6]}$

Several interventions (educational or others) aimed at solving this major drawback have been proposed and the effectiveness of some of them has been evaluated in a number of studies. ${ }^{[5,7-12]}$ In this sense we have reported that an intervention based on healthcare management agreements with economic incentives and educational activities was associated with a quantitative and qualitative improvement of spontaneous reporting of ADRs by hospital physicians. ${ }^{[13]}$ Not only did the absolute number of spontaneous reports increase but so did the number of reports of serious or unexpected ADRs and ADRs associated with new drugs.

The pattern of adverse drug reactions notified by spontaneous reporting in hospitals has been described in a few studies. ${ }^{[14-19]}$ Furthermore, there are no studies assessing if the improvement in reporting in the hospital setting allows a more efficient detection of new drug safety issues or if it facilitates signal identification. The usefulness of an increase in spontaneous reporting depends on the increase in the number of meaningful reports that help in raising concerns. Therefore, the aim of this study was to analyze the effect of the spontaneous reporting increase after an intervention in the hospital on the features of the ADRs reported, the drugs involved and the signals identified. 


\section{METHODS}

A time series analysis was carried out at Vall d'Hebron University Hospital (Barcelona, Spain) from 1998 to 2005 in order to assess the effectiveness of a continuous multifaceted intervention for improving spontaneous reporting of ADRs by hospital physicians to the Pharmacovigilance Programme (PhVP) of the hospital. The intervention was based on health care management agreements between hospital managers and clinical services, and was initiated in 2003. A framework agreement between hospital managers and physicians included different commitments linked to economic incentives. One of the objectives for physicians was to increase their participation in the PhVP increasing the number of spontaneous ADR reports. This objective was integrated into other clinical objectives at three levels: a) institution or whole hospital, b) clinical department or clinical team, and c) physician. The financial incentive obtained was variable according to the objectives achieved, and was approximately 5-7\% of the physician's salary. The size of the financial payment for ADR reporting accounted for less than $10 \%$ of the total of agreed incentives and was, on average, less than $1 \%$ of the physician's salary. In each clinical service, an initial meeting between physicians and the hospital pharmacovigilance team was held. In this first meeting, the hospital's pharmacovigilance activities, the aim of spontaneous ADR reporting and how to report ADRs, were presented. In addition to reinforcement, twice-yearly educational meetings were held in each clinical service, offering information about pharmacovigilance and emphasizing the priorities for spontaneous reporting ADRs (serious ADRs, unexpected ADRs, and those ADRs associated with new drugs). These meetings lasted 45-60 minutes, and consisted of a brief explanation of the number and main characteristics of ADRs detected in the whole hospital and in the specific clinical service. Signals identified by the PhVP and news about ADRs released by regulatory agencies were also commented on. Finally, reminder cards with the telephone number of the pharmacovigilance team and a list of the most important ADRs to be reported on (serious, unexpected and those associated with new drugs) were distributed to the hospital wards. 
Changes between the two periods of study (the $1^{\text {st }}$ period without intervention from 1998 to 2002 and the $2^{\text {nd }}$ period with intervention from 2003 to 2005) in the total number of spontaneous reports of ADRs, and in the number of serious reports, reports of unexpected ADRs and reports of ADRs related to recently marketed drugs were therein presented. ${ }^{[13]}$

In this paper, changes between the two periods in the following variables of the longitudinal study have been analyzed: (a) The patients' characteristics, such as gender and age; (b) the reported ADRs, with their seriousness, outcome, medical assistance required, and previous knowledge; (c) the suspected drugs involved in the ADRs, including those recently marketed; and (d) the most frequent drug-ADR associations and the main signals identified.

The ADRs were classified in organ-system categories according to the World Health Organization terminology (WHOART - WHO Adverse Reaction Terminology). The suspected drugs were grouped in therapeutic classes according to the Anatomical Therapeutic Chemical classification system. The seriousness of the cases was classified according to the European Union's criteria and cases were considered serious (ADRs that result in death, are lifethreatening, require hospitalisation or prolongation of existing hospitalisation, result in persistent or significant disability or incapacity, are congenital anomaly or birth defect, or are important medical events) or non -serious (the remaining cases) ${ }^{[21]}$ Its outcome was classified into recovery, permanent sequelae, death or unknown. According to the medical attention required, the cases were classified into those requiring hospital admission, in-hospital cases, cases requiring attention at the emergency room, and cases from the outpatient department. Previous knowledge of the ADRs was classified according to the Spanish Pharmacovigilance System's (SPhVS) causality algorithm in well-known ADRs, known from anecdotal reports, or unknown. ${ }^{[22]}$ New-drugs were defined as those marketed for less than five years at the time when the ADRs began. 
Statistical analysis. The spontaneous reports of ADRs during the two studied periods were analyzed separately. Descriptive analysis of continuous variables was performed by means of median and range; and statistical differences were assessed by means of the Mann-Whitney test. Categorical variables were described using percentages; statistical differences were assessed by means of the $\chi^{2}$ test. Significance was set at a level of 0.05 , two tailed. The statistical analysis was performed using the SPSS version 15.0 statistical package (SPSS Inc. Chicago-Illinois).

\section{RESULTS}

\section{Number of spontaneous reports of adverse drug reactions}

Of the total number of cases of ADRs identified by the PhVP, the proportion of spontaneous ADR reports increased from 29.5\% $(n=200)$ during the first period to $71.5 \%(n=631)$ during the second period. More details about this increase were presented in the previous paper.

\section{Patients' characteristics}

Gender and age distribution of patients described in the spontaneous reports were no different between the two periods. The ratio female-to-male in the spontaneous reports from the first period was 1.08 (104 females and 96 males); it was 0.96 in the second one ( 310 females and 321 males; $p=0.516$ ). Median age (minimum-maximum) was 64 (14-94) for patients described in both periods $(p=0.150)$.

\section{Medical attention required}

Most cases reported during the first period either required medical attention at the emergency room without hospital admission (99; $49.5 \%)$ or were in- 
hospital cases (99; 49.5\%). The two remaining cases (1\%) required hospital admission.

The number of cases requiring only medical attention at emergency room decreased during the second period (30; 4.8\%). In-hospital cases slightly decreased in relative terms although the absolute number of reports increased (277; 43.9\%). Conversely, cases requiring hospital admission increased both in relative and in absolute terms (236; 37.4\%). On the other hand, cases from outpatient department not requiring attention at the emergency room or hospital admission began to be reported during the second period, accounting for $13.9 \%$ (88) of the overall reports received at the end of this period ( $p<$ 0.001).

\section{Seriousness and outcome}

In the second period, the proportion of serious cases almost doubled $(63.1 \%$ vs $32.5 \%$ ) and the number of serious cases increased by more than 6-fold (398 vs 65; $p<0.001)$.

The most frequently reported outcome in both periods was recovery (70\% in the first one and $74.2 \%$ in the second one). The number of cases that recovered with sequelae was 2 in the first period and 16 in the second one. There were 9 fatal cases during the first period and 15 in the second one. The adverse reactions and drugs involved in these fatal cases are presented below in the drug-reaction associations section. Finally, the outcome was unknown in 49 cases in the first period and 132 in the second one $(p=0.153)$.

\section{$\underline{\text { Adverse reactions }}$}

Overall, 220 adverse reactions were described in the 200 first-period spontaneous reports. Cutaneous reactions were the most frequent, followed by cardiovascular and neurological reactions. In the 631 second-period 
spontaneous reports, 694 adverse reactions were described. Cutaneous reactions were the most frequent as well, followed in this case by haematological and gastrointestinal reactions (table 1). However, during the second period the frequency of endocrinological, urinary and hepatic reactions increased (3.7\% vs. $0.5 \%, 4.6 \%$ vs. $1.8 \%$ and $9.2 \%$ vs. $5.5 \%$, respectively).

The most commonly reported individual adverse reactions (with a frequency $\geq$ $3 \%$ of reports) during the first period were urticaria, angioedema, bronchospasm, hypotension, and haematoma. In the second period, individual reactions described in $\geq 3 \%$ of reports were rash and erythematous rash (table 2). During the second period the frequency of hyperthyroidism, thrombocytopenia and gastrointestinal haemorrhage increased by 4.3 and more than 2-fold, respectively.

\section{Suspected drugs}

Two hundred and eighty-five and 877 suspected pharmacological exposures were contained in the reports in the first and the second period respectively. In both periods, the most common therapeutic subgroups were systemic antibiotics, antithrombotics, and cardiac therapy. These three groups accounted for $38.2 \%$ and $30.3 \%$ of the total suspected pharmacological exposures in each period respectively (table 3 ). Regarding the remaining therapeutic subgroups, the greatest changes between periods were the increase in the proportion of immunostimulants, beta blocking agents, immunosuppressants and psychoanaleptics, and the decrease in the proportion of systemic antihistamines during the second period.

The drugs with the highest number of suspected exposures were amiodarone, amoxicillin-clavulanic acid, metamizole, and enoxaparin in both periods (table 4). Some drugs with no suspected exposures during the first period appeared during the second one (i.e., ceftriaxone, methotrexate, and tacrolimus). 
Additionally, a 9-fold increase was seen in the number of suspected exposures to ibuprofen, azithromycin and fluoxetine during the second period.

In both study periods, around $10 \%$ of suspected pharmacological exposures concerned recently marketed drugs. Nevertheless, both the overall number of suspected pharmacological exposures and the number of different drugs increased in the second period ( 97 vs. 28 , and 50 vs. 19 , respectively). The new drugs with the highest number of suspected exposures were clopidogrel, levofloxacin, and nevirapine (three exposures each) in the first period, and linezolid (eight exposures), tiotropium bromide, glatiramer acetate, oxcarbazepine, tenofovir, and voriconazole (five exposures each) in the second one.

\section{Drug-reaction associations}

In the first period, the most frequently reported drug-reaction associations were haemoperitoneum, retroperitoneal haemorrhage or muscular haematoma due to enoxaparin (11 cases, 5.5\% of reports). In the second period, they were hepatotoxicity induced by amoxicillin-clavulanic acid and hyperthyroidism due to amiodarone (14 cases and $2.2 \%$ of reports each) (table 5).

Three out of nine fatal reports from the first period were cases of haemorrhagic reactions in patients treated with enoxaparin (two retroperitoneal haemorrhages and a gastrointestinal bleeding), three were cases of cardiovascular reactions (myocardial infarction after terbutaline treatment, salbutamol and levofloxacin-induced torsade de pointes, and cardiac arrest in a patient treated with levomepromazine and carbamazepine) and the remaining three reports described adverse reactions related to other systems. The most frequent reactions in the fifteen fatal cases reported during the second period were also haemorrhagic events (seven cases). There were four cases of intracranial haemorrhage (three of them with tenecteplase, enoxaparin and acetylsalicylic acid, and one with drotrecogin alpha and enoxaparin), one case 
of enoxaparin-induced retroperitoneal haemorrhage, one case of intraabdominal haemorrhage due to enoxaparin, acenocoumarol and acetylsalicylic acid, and one case of acetylsalicylic acid-induced gastrointestinal haemorrhage. Of the eight remaining cases, three were toxic epidermal necrolysis and the other described reactions related to other systems.

\section{Previous knowledge/Signals identified}

The absolute number of previously unknown or poorly known drug-reaction associations had a fourfold increase in the second period (54 vs. 13 in the first period). Most of them were serious cases (5 out of 13 in the first period and 40 out of 54 in the second one; $p=0.047$ ).

No signals were identified during the first period. In the second one, two serious and previously unknown or poorly known drug-reaction associations were considered signals that required the adoption of regulatory measures by the Spanish Agency for Medicines and Medical Devices (AEMPS). The first signal was pseudoproteinuria induced by gelatine succinate infusion. A warning regarding this problem was added in the summary of product characteristics ${ }^{\text {[23] }}$ and a "Dear Dr letter" was sent to Spanish nephrologists and to the National Transplant Organization. The second signal was veralipride withdrawal syndrome; it required a risk-benefit assessment of the use of this orthopramide in the treatment of menopausal hot flushes and, as a result, the AEMPS withdrew this drug from the market. ${ }^{[24]}$ Afterwards, the EMEA also recommended the withdrawal of this drug from the European market. ${ }^{[25]}$

Additionally, the fatal case of cerebral haemorrhage due to drotrecogin alfa activated, which occurred in a patient who had recently undergone surgery, led to a review of safety data of this drug in the surgical population. As a result, the AEMPS proposed changes in the authorized conditions of use of drotrecogin alfa activated at the EMEA level. Those proposals contributed to updating the authorized conditions of use and contraindications of this drug. ${ }^{[26]}$ 


\section{DISCUSSION}

Our study has been the first one to assess the effect of a specific intervention on the features of ADRs spontaneously reported in a hospital setting, the drugs involved and the number of signals identified. It has shown that the improvement in spontaneous reporting of ADRs achieved following an intervention based on educational activities and economic incentives allowed us to detect some safety problems and to identify several signals. It is noteworthy that the reporting of all kind of adverse reactions and drugs increased.

The traditional methods and systems to detect ADRs in hospitals have been spontaneous reporting, intensive surveillance of hospital admissions and, more recently, computer-assisted approaches using routine data from hospital information systems. ${ }^{[3]}$ Different methods identify different types of ADRs and drugs. Moreover, the type of suspect drugs, their rank order and the types of ADRs identified vary widely among studies. In studies that only or predominantly included ADR-related hospitalisations, nonsteroidal antiinflammatory drugs causing gastrointestinal bleeding play a major role, followed by cardiovascular drugs and drugs acting on the central nervous system. In contrast, antibacterials/antiinfectives very often cause ADRs in hospitalised patients (mainly allergic reactions), as do opioids, cardiovascular drugs and

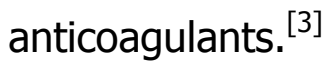

In our study the most frequently reported ADRs were similar in both periods, although some types of ADRs that were hardly reported on the first period increased in the second one. Cutaneous reactions were the most frequently reported ADRs in both periods: other ADRs commonly reported during both periods were cardiovascular, haematological, neurological and gastrointestinal reactions. Nevertheless, a high increase in endocrinological, urinary and hepatic 
reactions was observed in the second period. There are no other published studies comparing the effect of an intervention on the organ-system categories of reactions spontaneously reported in a hospital. A few studies have reported the pattern of spontaneously reported ADRs in hospitals. ${ }^{[16-19,27,28]}$ As in ours, in the majority of these studies dermatological reactions were the most frequently identified ${ }^{[17-19,27]}$ and skin rash was the most commonly reported reaction. ${ }^{[17,18]}$ Other ADRs such as neurological, gastrointestinal, and haematological reactions were also frequently reported. However, it is interesting to note that, in contrast with our study, endocrinological and urinary reactions were rarely reported in others. In our opinion, the intervention could be responsible for the increase in the reporting of these ADRs in the second period. Further studies should be carried out to analyze the effect of different interventions on the features of the spontaneously reported ADRs.

The majority of therapeutic subgroups of suspected drugs increased during the intervention. Systemic antibiotics, antithrombotics, and cardiac therapy drugs were the most commonly involved therapeutic subgroups in the spontaneous reports in both periods. These therapeutic subgroups were also frequently reported in other studies that assessed the drugs involved in spontaneously reported ADRs in hospitals. ${ }^{[18,19,27]}$ In our study, the greatest changes between periods were the increase in the proportion of immunostimulants, immunosuppressants and psychoanaleptics. In addition, antineoplastics, a therapeutic subgroup highly reported in other studies, ${ }^{[17,19,27]}$ also increased during the intervention. The therapeutic subgroups most commonly involved in the spontaneously reported ADRs were drugs frequently used in the hospital setting. Nevertheless, taking into account the differences in the pattern of suspect drugs in the two periods, it is likely that the intervention allowed us to identify during the second period some suspect drugs involved in ADRs infrequently reported in the first one. It would be interesting to investigate the effect of other interventions on the type of suspected drugs in spontaneously reported ADRs. 
Furthermore, the absolute number of spontaneous reports from any origin increased during the second period, except for those from emergencies. It is worth noting that spontaneous reports from the outpatient hospital consultations began to be reported during the second period. The effect of the intervention was evident, since the physicians had been informed in the educational meetings that they could report ADRs from every assistance setting. Unexpectedly, spontaneous reporting of ADRs requiring only medical attention at emergency room did not increase in spite of the intervention. The reason for that is unknown, although high attendance-pressure, specially in this area, lack of time, and other clinical priorities have been argued as potential obstacles to the spontaneous reporting of ADRs by the doctors at our hospital. ${ }^{[5]}$ Therefore, in the emergency area some other specific strategies aimed at increasing spontaneous reporting should be planned.

One of the main objectives of spontaneous reporting of ADRs is to detect drug safety concerns related to new drugs. Surprisingly, the novelty of suspect drugs has not been analyzed in published studies on spontaneous reporting in hospitals. In our study we observed that during the intervention the number of suspected pharmacological exposures to recently marketed drugs and the number of serious cases, including those with a fatal outcome, increased. It is noteworthy that one of the signals identified referred to a serious reaction to a recently marketed drug and arose through the reporting of a fatal case (i.e. intracranial haemorrhage associated to drotecogin alfa activated).

The majority of drug-reaction associations spontaneously reported in both periods of the study were well-known reactions related to old drugs (i.e., haemorrhage due to enoxaparin, hepatotoxicity due to amoxicillin-clavulanic acid, and hyperthyroidism due to amiodarone). However, the reporting of known ADRs can help to identify local problems related to the use of specific drugs. For example, in our hospital haemorrhages related to low-weight molecular heparins led to an analysis of the severe cases in order to identify possible risk factors. On the other hand, two previously unknown reactions 
associated with old drugs that were reported in the second period led to the withdrawal of the market of one drug and an update of the summary of product characteristics in the other one. This point is interesting because it shows that even old drugs must be kept under surveillance through their entire life-span to detect some possible previously unknown reactions.

Obviously our study has some limitations. First of all, it was carried out in only one hospital with specific characteristics (a teaching tertiary hospital; the biggest one in our geographical area). Additionally, the Catalan Centre of the Spanish Pharmacovigilance System is located in the hospital. Therefore, our findings could not be generalized to other hospitals. Secondly, since our study was a time series study without a control group, we can not rule out the influence of other factors in the observed results. Nevertheless, the number of the spontaneous ADRs reported by the other Catalan hospital to the Pharmacovigilance regional Centre during the two study's periods did not increase. Thirdly, the number of signals identified was low and we can not confirm the effect of intervention on its detection. Fourthly, we did not collect information on the category of physicians, medical speciality and other characteristics of the reporters that might have influenced the results. In spite of all these limitations, our study generates new information on the effect of a specific intervention on the features of the spontaneously reported ADRs, the drugs involved and the signals identified. On the one hand, that confirms the usefulness of the implementation of these types of strategies to improve reporting of ADRs in hospitals. On the other hand, these results can be and even should be used as an argument when stimulating the spontaneous reporting by health care professionals by means of supporting evidence of the usefulness of pharmacovigilance activities.

As a conclusion, an intervention based on educational activities and economic incentives led not only to a quantitative improvement in spontaneous reporting of ADRs by hospital physicians but also to a qualitative improvement in terms of seriousness of reactions identified affecting different organs or systems, and 


\section{Acknowledgments}

The authors would like to thank the hospital physicians who participated in this study for their collaboration. No sources of funding were used to assist in the development of this study. The authors have no conflicts of interest that are directly relevant to the content of this study. 


\section{References}

1. Wysowski DK, Swartz L. Adverse drug event surveillance and drug withdrawals in the United States, 1969-2002: the importance of reporting suspected reactions. Arch Intern Med 2005; 165: 1363-9

2. Aronson, JK. Adverse drug reactions - no farewell to harms. Br J Clin Pharmacol 2007; 63: 131-5

3. Thürmann PA. Methods and systems to detect adverse drug reactions in hospitals. Drug Safety 2001; 24: 961-8

4. Rawlins MD. Pharmacovigilance; paradise lost, regained or postponed?. The William Withering Lecture 1994. J R Coll Physicians Lond 1995; 29: 41-9

5. Vallano A, Cereza G, Pedros C, Agusti A, Danes I, Aguilera C, Arnau JM. Obstacles and solutions for spontaneous reporting of adverse drug reactions in the hospital. Br J Clin Pharmacol 2005; 60: 653-8

6. Moride Y, Haramburu F, Requejo AA, Begaud B. Under-reporting of adverse drug reactions in general practice. Br J Clin Pharmacol 1997; 43: 177-81

7. Figueiras A, Herdeiro MT, Polonia J, Gestal-Otero JJ. An educational intervention to improve physician reporting of adverse drug reactions: a clusterrandomized controlled trial. JAMA 2006; 296: 1086-93.

8. Nazario M, Feliu JF, Rivera GC. Adverse drug reactions: the San Juan Department of Veterans Affairs Medical Center experience. Hosp Pharm 1994; 29: $244-50$ 
9. Scott HD, Thacher-Renshaw A, Rosenbaum SE, Waters WJ Jr, Green M, Andrews LG, Faich GA. Physician reporting of adverse drug reactions. Results of the Rhode Island Adverse Drug Reaction Reporting Project. JAMA 1990; 263: $1785-8$

10. Fincham J. A statewide program to stimulate reporting of adverse drug reactions. J Pharm Pract 1989; 2: 239-44

11. McGettigan P, Golden J, Conroy RM, Arthur N, Feely J. Reporting of adverse drug reactions by hospital doctors and the response to intervention. $\mathrm{Br} \mathrm{J}$ Clin Pharmacol 1997; 44: 98-100

12. Kimelblatt BJ, Young SH, Heywood PM, Mandala AR, Gendelman S, Mehl B. Improved reporting of adverse drug reactions. Am J Hosp Pharm 1988; 45: 1086-9

13. Pedrós C, Vallano A, Cereza G, Mendoza-Aran G, Agustí A, Aguilera C, Danés I, Vidal $X$, Arnau JM. An intervention to improve spontaneous adverse drug reaction reporting by hospital physicians. A time series analysis in Spain. Drug Safety 2009; 32: 77-83

14. Maistrello I, Morgutti M, Maltempi M, Dantes M. Adverse drug reactions in hospitalized patients: an operational procedure to improve reporting and investigate underreporting. Pharmacoepidemiol Drug Saf 1995; 4: 101-6

15. Cox AR, Anton C, Goh CHF, Easter M, Langford NJ, Ferner RE. Adverse drug reactions in patients admitted to hospital identified by discharge ICD-10 codes and by spontaneous reports. $\mathrm{Br}$ J Clin Pharmacol 2001; 52: 337-9

16. Ortega A, Aguinagalde A, Lacasa C, Aquerreta I, Fernández-Benítez M, Fernández LM. Efficacy of an adverse drug reaction electronic reporting system 
integrated into a hospital information system. Ann Pharmacother 2008; 42: 1491-6

17. Jose J, Rao PGM. Pattern of adverse drug reactions notified by spontaneous reporting in an Indian tertiary care teaching hospital. Pharmacological Research 2006; 54: 226-33

18. Arulmani $R$, Rajendran SD, Suresh B. Adverse drug reaction monitoring in a secondary care hospital in South India. Br J Clin Pharmacol 2007; 65: 210-16

19. Baniasadi S, Fahimi F, Shalviri G. Developing an adverse drug reaction reporting system at a teaching hospital. Basic \& Clinical Pharmacology \& Toxicology 2008; 102: 408-11

20. Edwards R. Adverse drug reactions: finding the needle in the haystack. $\mathrm{Br}$ Med J 1997; 315: 500

21. Commission Directive 2000/38/EC of 5 June 2000 amending Chapter Va (Pharmacovigilance) of Council Directive 75/319/EEC on the approximation of provisions laid down by law, regulation or administrative action relating to medicinal products. Official Journal of the European Communities 10.6.2000: L139/28-L139/30 [online]. Available from URL: http://eurlex.europa.eu/LexUriServ/LexUriServ.do?uri=OJ:L:2000:139:0028:0030:EN:PDF [Accessed 2009 September 10]

22. Capellà D, Laporte J-R. La notificación espontánea de reacciones adversas a medicamentos. In: Laporte J-R, Tognoni G, editors. Principios de epidemiología del medicamento. $2^{\text {nd }}$ ed. Barcelona: Masson-Salvat, 1993: 147-70

23. Spanish Agency of Medicines and Health Products. Product Information. Gelafundina ${ }^{\circledR}$.

https://sinaem4.agemed.es/consaem/especialidad.do?metodo=verFichaWordPd 
$\underline{f \& \text { codigo }=61627 \& \text { formato }=\text { pdf\&formulario=FICHAS }}$ [Accessed 2009 September 10]

24. Spanish Agency of Medicines and Health Products. Informative note. Recommendations for the withdrawal of the treatment with Agreal ${ }^{\circledR}$ (Veralipride). http://www.agemed.es/actividad/alertas/docs/NI 200515 AGREAL.pdf [Accessed 2009 September 10]

25. European Medicines Agency. Questions and answers on the recommendation to withdraw the marketing authorisation of veralipride. http://www.emea.europa.eu/pdfs/human/referral/agreal/29946807en.pdf [Accessed 2009 September 10]

26. European Medicines Agency. Xigris. Procedural steps taken and scientific information after the authorisation. Changes made after 01/10/2004. http://www.emea.europa.eu/humandocs/PDFs/EPAR/xigris/H-396-en8b.pdf [Accessed 2009 September 10]

27. Uppal R, Jhaj R, Malhotra S. Adverse drug reactions among inpatients in a north Indian referral hospital. Natl Med J India 2000; 13: 16-8

28. Lugardon S, Desboeuf K, Fernet $P$, Monstastruc J-L, Lapeyre-Mestre M. Using a capture-recapture method to assess the frequency of adverse drug reactions in a French university hospital. Br J Clin Pharmacol 2006; 62: 225-31 
Table 1. Adverse drug reactions classified by organ or system affected

\begin{tabular}{lcccc}
\hline \multicolumn{1}{c}{ Organ or system } & \multicolumn{2}{c}{ First period } & \multicolumn{2}{c}{ Second period } \\
& $\mathrm{N}$ & $(\%)$ & $\mathrm{N}$ & $(\%)$ \\
\hline Cutaneous reactions & 44 & $(20.0)$ & 128 & $(18.4)$ \\
Haematological reactions & 23 & $(10.5)$ & 68 & $(9.8)$ \\
Gastrointestinal reactions & 19 & $(8.6)$ & 68 & $(9.8)$ \\
Cardiovascular reactions & 27 & $(12.3)$ & 67 & $(9.7)$ \\
Hepatic reactions & 12 & $(5.5)$ & 64 & $(9.2)$ \\
Neurological reactions & 26 & $(11.8)$ & 58 & $(8.4)$ \\
Metabolic and nutritional reactions & 10 & $(4.5)$ & 43 & $(6.2)$ \\
Respiratory reactions & 19 & $(8.6)$ & 39 & $(5.6)$ \\
General disorders & 9 & $(4.1)$ & 37 & $(5.3)$ \\
Urinary reactions & 4 & $(1.8)$ & 32 & $(4.6)$ \\
Endocrinological reactions & 1 & $(0.5)$ & 26 & $(3.7)$ \\
Psychiatric reactions & 12 & $(5.5)$ & 24 & $(3.5)$ \\
Others & 14 & $(6.3)$ & 40 & $(5.8)$ \\
\hline Total & 220 & $(100)$ & 694 & $(100)$ \\
\hline
\end{tabular}


1

6

Table 2. Most frequent adverse reactions

\begin{tabular}{|c|c|c|c|c|}
\hline \multirow[t]{2}{*}{ Adverse reaction } & \multicolumn{2}{|c|}{$\begin{array}{l}\text { First period } \\
(\mathrm{N}=220)\end{array}$} & \multicolumn{2}{|c|}{$\begin{array}{l}\text { Second period } \\
\qquad(N=694)\end{array}$} \\
\hline & $\mathrm{N}$ & $(\%)$ & $\mathrm{N}$ & $(\%)$ \\
\hline Erythematous rash & 5 & $(2.3)$ & 31 & $(4.5)$ \\
\hline Rash & 6 & $(2.7)$ & 25 & $(3.6)$ \\
\hline Hepatitis & 3 & $(1.4)$ & 20 & $(2.9)$ \\
\hline Thrombocytopenia & 2 & $(0.9)$ & 19 & $(2.7)$ \\
\hline Hepatic enzymes increased & 6 & $(2.7)$ & 18 & $(2.6)$ \\
\hline Acute renal failure & 4 & $(1.8)$ & 18 & $(2.6)$ \\
\hline Hepatitis cholestatic & 3 & $(1.4)$ & 17 & $(2.4)$ \\
\hline Gastrointestinal haemorrhage & 2 & $(0.9)$ & 17 & $(2.4)$ \\
\hline Diarrhoea & 3 & $(1.4)$ & 16 & $(2.3)$ \\
\hline Anaphylactic shock & 4 & $(1.8)$ & 15 & $(2.2)$ \\
\hline Heart failure & 2 & $(0.9)$ & 14 & $(2.0)$ \\
\hline Hyperthyroidism & 1 & $(0.5)$ & 14 & $(2.0)$ \\
\hline Urticaria & 10 & $(4.5)$ & 12 & $(1.7)$ \\
\hline Angioedema & 9 & $(4.1)$ & 11 & $(1.6)$ \\
\hline Bronchospasm & 9 & $(4.1)$ & 10 & $(1.4)$ \\
\hline Haematoma & 8 & (3.6) & 9 & $(1.3)$ \\
\hline Atrioventricular block & 4 & $(1.8)$ & 8 & $(1.2)$ \\
\hline Encephalopathy & 4 & $(1.8)$ & 8 & $(1.2)$ \\
\hline Extrapiramidal disorder & 5 & $(2.3)$ & 4 & $(0.6)$ \\
\hline Retroperitoneal haemorrhage & 6 & $(2.7)$ & 3 & $(0.4)$ \\
\hline Distonia & 5 & $(2.3)$ & 3 & $(0.4)$ \\
\hline Hypotension & 9 & $(4.1)$ & 2 & $(0.3)$ \\
\hline
\end{tabular}

Only adverse reactions present in at least five reports of any period are displayed. 
Table 3. Suspect drugs by therapeutic subgroup

\begin{tabular}{lcccc}
\hline \multirow{2}{*}{ Therapeutic subgroup } & \multicolumn{2}{c}{ First period } & \multicolumn{2}{c}{ Second period } \\
\cline { 2 - 5 } & $\mathrm{N}$ & $(\%)$ & $\mathrm{N}$ & $\%$ \\
\hline Systemic antibiotics (J01) & 62 & $(21.8)$ & 149 & $(17.0)$ \\
Antithrombotics (B01) & 30 & $(10.5)$ & 69 & $(7.9)$ \\
Cardiac therapy (C01) & 17 & $(6.0)$ & 47 & $(5.4)$ \\
Antiinflammatories and antirheumatics (M01) & 12 & $(4.2)$ & 46 & $(5.2)$ \\
Psychoanaleptics (N06) & 8 & $(2.8)$ & 44 & $(5.0)$ \\
Analgesics (N02) & 17 & $(6.0)$ & 35 & $(4.0)$ \\
Drugs acting on the renin-angiotensin system (C09) & 10 & $(3.5)$ & 35 & $(4.0)$ \\
Antiepileptics (N03) & 9 & $(3.1)$ & 35 & $(4.0)$ \\
Antineoplastics (L01) & 8 & $(2.8)$ & 34 & $(3.9)$ \\
Antimycobacterials (J04) & 14 & $(4.9)$ & 32 & $(3.6)$ \\
Systemic antivirals (J05) & 7 & $(2.5)$ & 31 & $(3.5)$ \\
Immunosuppressive drugs (L04) & 4 & $(1.4)$ & 29 & $(3.3)$ \\
Diuretics (C03) & 9 & $(3.1)$ & 27 & $(3.1)$ \\
Psycholeptics (N05) & 9 & $(3.1)$ & 24 & $(2.7)$ \\
Drugs for obstructive airway diseases (R03) & 6 & $(2.1)$ & 22 & $(2.5)$ \\
Beta blocking drugs (C07) & 3 & $(1.1)$ & 22 & $(2.5)$ \\
Immunostimulants (L03) & 0 & $(-)$ & 18 & $(2.1)$ \\
Systemic corticosteroids (H02) & 4 & $(1.4)$ & 16 & $(1.8)$ \\
Lipid modifying drugs (C10) & 6 & $(2.1)$ & 15 & $(1.7)$ \\
Systemic antihistamines (R06) & 11 & $(3.9)$ & 4 & $(0.5)$ \\
Others & 39 & $(13.7)$ & 143 & $(16.3)$ \\
\hline Total & 285 & $(100)$ & 877 & $(100)$ \\
\hline
\end{tabular}


Table 4. Most frequent suspect drugs

\begin{tabular}{|c|c|c|c|c|c|c|}
\hline \multirow{3}{*}{ Drug } & \multicolumn{3}{|c|}{ First period } & \multicolumn{3}{|c|}{ Second period } \\
\hline & \multicolumn{2}{|c|}{$\begin{array}{l}\text { Suspect exposures } \\
\qquad(\mathrm{N}=285)\end{array}$} & \multirow{2}{*}{$\begin{array}{c}\text { Reports } \\
(\mathrm{N}=200)\end{array}$} & \multicolumn{2}{|c|}{$\begin{array}{l}\text { Suspect exposures } \\
\qquad(\mathrm{N}=877)\end{array}$} & \multirow{2}{*}{$\begin{array}{c}\begin{array}{c}\text { Reports } \\
(\mathrm{N}=631)\end{array} \\
\%\end{array}$} \\
\hline & $\mathrm{N}$ & $(\%)$ & & $\mathrm{N}$ & $(\%)$ & \\
\hline Amiodarone & 11 & (3.9) & 5.5 & 36 & $(4.1)$ & 5.7 \\
\hline Amoxicillin-clavulanic acid & 16 & $(5.6)$ & 8.0 & 35 & (3.9) & 5.5 \\
\hline Metamizole & 12 & $(4.2)$ & 6.0 & 23 & $(2.6)$ & 3.6 \\
\hline Enoxaparin & 16 & $(5.6)$ & 8.0 & 21 & (2.4) & 3.3 \\
\hline Enalapril & 4 & (1.4) & 2.0 & 21 & (2.4) & 3.3 \\
\hline Ibuprofen & 2 & $(0.7)$ & 1.0 & 18 & (2.1) & 2.9 \\
\hline Acenocoumarol & 2 & $(0.7)$ & 1.0 & 15 & (1.7) & 2.4 \\
\hline Acetylsalicylic acid & 6 & $(2.1)$ & 3.0 & 14 & (1.6) & 2.2 \\
\hline Prednisone & 2 & $(0.7)$ & 1.0 & 13 & (1.5) & 2.1 \\
\hline Phenytoin & 3 & $(1.1)$ & 1.5 & 10 & (1.1) & 1.6 \\
\hline Levofloxacin & 3 & $(1.1)$ & 1.5 & 10 & (1.1) & 1.6 \\
\hline Pyrazinamide & 3 & $(1.1)$ & 1.5 & 10 & (1.1) & 1.6 \\
\hline Furosemide & 3 & (1.1) & 1.5 & 9 & $(1.0)$ & 1.4 \\
\hline Azithromycin & 1 & $(0.4)$ & 0.5 & 9 & $(1.0)$ & 1.4 \\
\hline Fluoxetine & 1 & $(0.4)$ & 0.5 & 9 & $(1.0)$ & 1.4 \\
\hline Ciprofloxacin & 6 & $(2.1)$ & 3.0 & 8 & $(0.9)$ & 1.3 \\
\hline Spironolactone & 1 & $(0.4)$ & 0.5 & 8 & $(0.9)$ & 1.3 \\
\hline Linezolid & 0 & $(-)$ & - & 8 & $(0.9)$ & 1.3 \\
\hline Diclofenac & 6 & $(2.1)$ & 3.0 & 7 & $(0.8)$ & 1.1 \\
\hline Hydrochlorothiazide & 3 & $(1.1)$ & 1.5 & 7 & $(0.8)$ & 1.1 \\
\hline Cefepime & 2 & $(0.7)$ & 1.0 & 7 & $(0.8)$ & 1.1 \\
\hline Rifampicin-isoniazid & 1 & $(0.4)$ & 0.5 & 7 & $(0.8)$ & 1.1 \\
\hline Clarithromycin & 5 & $(1.8)$ & 2.5 & 6 & $(0.7)$ & 1.0 \\
\hline Carbamazepine & 3 & $(1.1)$ & 1.5 & 6 & $(0.7)$ & 1.0 \\
\hline Digoxin & 3 & $(1.1)$ & 1.5 & 6 & $(0.7)$ & 1.0 \\
\hline Moxifloxacin & 2 & $(0.7)$ & 1.0 & 6 & $(0.7)$ & 1.0 \\
\hline Azathioprine & 1 & $(0.4)$ & 0.5 & 6 & $(0.7)$ & 1.0 \\
\hline Vancomycin & 1 & $(0.4)$ & 0.5 & 6 & $(0.7)$ & 1.0 \\
\hline Ceftriaxone & 0 & $(-)$ & - & 6 & $(0.7)$ & 1.0 \\
\hline Methotrexate & 0 & $(-)$ & - & 6 & $(0.7)$ & 1.0 \\
\hline Tacrolimus & 0 & $(-)$ & - & 6 & $(0.7)$ & 1.0 \\
\hline Thiethylperazine & 8 & (2.8) & 4.0 & 3 & $(0.3)$ & 0.5 \\
\hline
\end{tabular}

Only drugs with at least six suspect exposures in any period are displayed. 
Table 5. Most frequent drug-reaction associations

\begin{tabular}{|c|c|c|c|c|c|}
\hline \multirow[t]{2}{*}{ Drug } & \multirow[t]{2}{*}{ Reaction } & \multicolumn{2}{|c|}{$\begin{array}{c}\text { First period } \\
(\mathrm{N}=200 \text { reports })\end{array}$} & \multicolumn{2}{|c|}{$\begin{array}{l}\text { Second period } \\
\text { (N=631 reports) }\end{array}$} \\
\hline & & $\mathrm{N}$ & $(\%)$ & $\mathrm{N}$ & $(\%)$ \\
\hline Amoxicillin-clavulanic acid & Hepatic enzymes increased, hepatitis or cholestatic hepatitis & 2 & $(1.0)$ & 14 & $(2.2)$ \\
\hline Amiodarone & Hyperthyroidism & 1 & $(0.5)$ & 14 & $(2.2)$ \\
\hline Enoxaparin & Haemoperitoneum, retroperitoneal haemorrhage or haematoma & 11 & $(5.5)$ & $8^{\mathrm{a}}$ & $(1.3)$ \\
\hline Acenocoumarol & Haemoperitoneum, retroperitoneal haemorrhage or haematoma & 1 & $(0.5)$ & $7^{\mathrm{a}}$ & $(1.1)$ \\
\hline Amiodarone & QT interval prolonged, torsade de pointes or ventricular fibrillation & 0 & $(-)$ & 7 & $(1.1)$ \\
\hline Phenytoin & Erythematous, maculopapular or unspecified rash & 1 & $(0.5)$ & 7 & $(1.1)$ \\
\hline Metamizole & Erythematous, maculopapular or unspecified rash & 1 & $(0.5)$ & 7 & $(1.1)$ \\
\hline Enalapril & Acute renal failure & 0 & $(-)$ & 6 & $(1.0)$ \\
\hline Prednisone & Hyperglycaemia, diabetes mellitus or diabetes mellitus aggravated & 0 & $(-)$ & 6 & $(1.0)$ \\
\hline Acetylsalicylic acid & Gastrointestinal haemorrhage & $1^{\mathrm{b}}$ & $(0.5)$ & $5^{c}$ & $(0.8)$ \\
\hline Enalapril & Cough & 0 & $(-)$ & 5 & $(0.8)$ \\
\hline Enoxaparin & Cerebral haemorrhage & 0 & $(-)$ & $5^{d}$ & $(0.8)$ \\
\hline Thiethylperazine & Distonia and/or dyskinesia & 7 & (3.5) & 3 & $(0.5)$ \\
\hline Amoxicillin-clavulanic acid & Angioedema or laryngeal oedema & 5 & $(2.5)$ & 0 & $(-)$ \\
\hline
\end{tabular}

Only associations present in at least five reports of any period are displayed.

a Concomitant administration of enoxaparin and acenocoumarol in two cases. ${ }^{b}$ Enoxaparin concomitantly administered. ' Drugs concomitantly administered: clopidogrel (in one case); clopidogrel, enoxaparin and abciximab (in one case); enoxaparin and streptokinase (in one case). ${ }^{\mathrm{d}}$ Drugs concomitantly administered: tenecteplase and acetylsalicylic acid (in four cases); drotrecogin alfa activated (in one case). 


\section{EFFECT OF AN INTERVENTION ON THE FEATURES OF ADVERSE DRUG REACTIONS SPONTANEOUSLY REPORTED IN A HOSPITAL}

Cereza $G^{1,2}$, Agustí $A^{1,3,4}$, Pedrós $C^{5}$, Vallano $A^{5,6}$, Aguilera $C^{1,3}$, Danés $I^{1,3,4}$, Vidal $\mathrm{X}^{1,3,4}$, Arnau $\mathrm{JM}^{5,6}$

${ }^{1}$ Fundació Institut Català de Farmacologia, Barcelona, Spain

${ }^{2}$ Catalan Centre of Pharmacovigilance, Barcelona, Spain

${ }^{3}$ Clinical Pharmacology Service, Hospital Universtari Vall d'Hebron, Barcelona, Spain

${ }^{4}$ Department of Pharmacology, Therapeutics, and Toxicology, Universitat Autònoma de Barcelona, Barcelona, Spain

${ }^{5}$ Clinical Pharmacology Service, Hospital Universitari de Bellvitge, Hospitalet de Llobregat, Spain

${ }^{6}$ Department of Pathology and Experimental Therapeutics, Universitat de Barcelona, Spain

Words account 3,579

Correspondence: Dr. Gloria Cereza

Fundació Institut Català de Farmacologia

Passeig Vall d'Hebron 119-129

08035 - Barcelona, Spain

E-mail: gcg@icf.uab.cat 


\section{ABSTRACT}

Background.- A continuous intervention based on healthcare management agreements was associated in our hospital with an increase in the absolute number of spontaneous reporting of adverse drug reactions (ADRs), and also with an increase in the number of reports of serious or unexpected ADRs and ADRs associated with new drugs.

Objective.- To analyze the effect of this intervention on the features of ADRs spontaneously reported in a hospital, the drugs involved and the number of signals identified.

Methods.- A longitudinal study with two periods, the $1^{\text {st }}$ period without intervention from 1998 to 2002 and the $2^{\text {nd }}$ period with intervention from 2003 to 2005, was carried out in a teaching tertiary Hospital. Changes between the two periods in the following variables were analysed: (a) the patients' characteristics, such as gender and age; (b) the reported ADRs, and their medical assistance required; (c) the suspected drugs involved in the ADRs and (d) the main signals identified.

Results.- Gender and age distribution of patients described in the spontaneous reports were no different in the two periods. During the second period, spontaneously reported cases requiring hospital admission and those occurring in-hospital increased (236 from 2 in the first period and 277 from 99 in the first period, respectively) and cases from outpatient hospital consultations began to be reported (13.9\% of reports). The spontaneous reporting on all kinds of ADRs and drugs increased during the second period. Cutaneous reactions were the most frequently spontaneous reported ADRs in both periods followed by cardiovascular and neurological reactions in the first period, and haematological and gastrointestinal reactions in the second one. However, during the second period the higher increase was for endocrinological, urinary and hepatic reactions. Systemic antibiotics, antithrombotics and cardiac therapy drugs were the most commonly therapeutic subgroups reported as suspected drugs in both periods, but in the second period the proportion of immunostimulants, beta blocking agents, immunosuppressants and psychoanaleptics increased. No 
signals were recognized during the first period, however two signals and one additional safety concern were identified during the second.

Conclusion.- An intervention based on healthcare management agreements, was associated with an important increase in spontaneous reporting of ADRs by hospital physicians and also with a change in terms of type of ADRs identified affecting different organs or systems, and the therapeutic groups of drugs involved. Future studies should analyze the effect of different types of intervention on spontaneous reporting of ADRs in hospitals.

Words account: 399

Keywords: Pharmacovigilance; Adverse Drug Reactions Reporting Systems;

Drug Toxicity; Intervention Studies; Hospital 


\section{INTRODUCTION}

The spontaneous reporting system is currently the cornerstone of postmarketing signal detection in pharmacovigilance. ${ }^{[1-2]}$ Detection of adverse drug reactions (ADRs) in hospitals is important because serious events may be identified, novel drugs are commonly used, new and unexpected ADRs may be detected early on and cases are usually well-documented with high quality information. Nevertheless, spontaneous reporting has been scarcely used as a method of ADRs detection in hospitals and underreporting is a major flaw, ${ }^{[3-5]}$ as it is in the primary health care setting. ${ }^{[6]}$

Several interventions (educational or others) aimed at solving this major drawback have been proposed and the effectiveness of some of them has been evaluated in a number of studies. ${ }^{[5,7-12]}$ In this sense we have reported that an intervention based on healthcare management agreements with economic incentives and educational activities was associated with a quantitative and qualitative improvement of spontaneous reporting of ADRs by hospital physicians. ${ }^{[13]}$ Not only did the absolute number of spontaneous reports increase but so did the number of reports of serious or unexpected ADRs and ADRs associated with new drugs.

The pattern of adverse drug reactions notified by spontaneous reporting in hospitals has been described in a few studies. ${ }^{[14-19]}$ Furthermore, there are no studies assessing if the improvement in reporting in the hospital setting allows a more efficient detection of new drug safety issues or if it facilitates signal identification. The usefulness of an increase in spontaneous reporting depends on the increase in the number of meaningful reports that help in raising concerns. Therefore, the aim of this study was to analyze the effect of the spontaneous reporting increase after an intervention in the hospital on the features of the ADRs reported, the drugs involved and the signals identified. 


\section{METHODS}

A time series analysis was carried out at Vall d'Hebron University Hospital (Barcelona, Spain) from 1998 to 2005 in order to assess the effectiveness of a continuous multifaceted intervention for improving spontaneous reporting of ADRs by hospital physicians to the Pharmacovigilance Programme (PhVP) of the hospital. The intervention was based on health care management agreements between hospital managers and clinical services, and was initiated in 2003. A framework agreement between hospital managers and physicians included different commitments linked to economic incentives. One of the objectives for physicians was to increase their participation in the PhVP increasing the number of spontaneous ADR reports. This objective was integrated into other clinical objectives at three levels: a) institution or whole hospital, b) clinical department or clinical team, and c) physician. The financial incentive obtained was variable according to the objectives achieved, and was approximately 5-7\% of the physician's salary. The size of the financial payment for ADR reporting accounted for less than $10 \%$ of the total of agreed incentives and was, on average, less than $1 \%$ of the physician's salary. In each clinical service, an initial meeting between physicians and the hospital pharmacovigilance team was held. In this first meeting, the hospital's pharmacovigilance activities, the aim of spontaneous ADR reporting and how to report ADRs, were presented. In addition to reinforcement, twice-yearly educational meetings were held in each clinical service, offering information about pharmacovigilance and emphasizing the priorities for spontaneous reporting ADRs (serious ADRs, unexpected ADRs, and those ADRs associated with new drugs). These meetings lasted 45-60 minutes, and consisted of a brief explanation of the number and main characteristics of ADRs detected in the whole hospital and in the specific clinical service. Signals identified by the PhVP and news about ADRs released by regulatory agencies were also commented on. Finally, reminder cards with the telephone number of the pharmacovigilance team and a list of the most important ADRs to be reported on (serious, unexpected and those associated with new drugs) were distributed to the hospital wards. 
Changes between the two periods of study (the $1^{\text {st }}$ period without intervention from 1998 to 2002 and the $2^{\text {nd }}$ period with intervention from 2003 to 2005) in the total number of spontaneous reports of ADRs, and in the number of serious reports, reports of unexpected ADRs and reports of ADRs related to recently marketed drugs were therein presented. ${ }^{[13]}$

In this paper, changes between the two periods in the following variables of the longitudinal study have been analyzed: (a) The patients' characteristics, such as gender and age; (b) the reported ADRs, with their seriousness, outcome, medical assistance required, and previous knowledge; (c) the suspected drugs involved in the ADRs, including those recently marketed; and (d) the most frequent drug-ADR associations and the main signals identified.

The ADRs were classified in organ-system categories according to the World Health Organization terminology (WHOART - WHO Adverse Reaction Terminology). The suspected drugs were grouped in therapeutic classes according to the Anatomical Therapeutic Chemical classification system. The seriousness of the cases was classified according to the European Union's criteria and cases were considered serious (ADRs that result in death, are lifethreatening, require hospitalisation or prolongation of existing hospitalisation, result in persistent or significant disability or incapacity, are congenital anomaly or birth defect, or are important medical events) or non -serious (the remaining cases). ${ }^{[21]}$ Its outcome was classified into recovery, permanent sequelae, death or unknown. According to the medical attention required, the cases were classified into those requiring hospital admission, in-hospital cases, cases requiring attention at the emergency room, and cases from the outpatient department. Previous knowledge of the ADRs was classified according to the Spanish Pharmacovigilance System's (SPhVS) causality algorithm in well-known ADRs, known from anecdotal reports, or unknown. ${ }^{[22]}$ New-drugs were defined as those marketed for less than five years at the time when the ADRs began. 
Statistical analysis. The spontaneous reports of ADRs during the two studied periods were analyzed separately. Descriptive analysis of continuous variables was performed by means of median and range; and statistical differences were assessed by means of the Mann-Whitney test. Categorical variables were described using percentages; statistical differences were assessed by means of the $\chi^{2}$ test. Significance was set at a level of 0.05 , two tailed. The statistical analysis was performed using the SPSS version 15.0 statistical package (SPSS Inc. Chicago-Illinois).

\section{RESULTS}

\section{Number of spontaneous reports of adverse drug reactions}

Of the total number of cases of ADRs identified by the PhVP, the proportion of spontaneous ADR reports increased from 29.5\% $(n=200)$ during the first period to $71.5 \%(n=631)$ during the second period. More details about this increase were presented in the previous paper.

\section{Patients' characteristics}

Gender and age distribution of patients described in the spontaneous reports were no different between the two periods. The ratio female-to-male in the spontaneous reports from the first period was 1.08 (104 females and 96 males); it was 0.96 in the second one ( 310 females and 321 males; $p=0.516$ ). Median age (minimum-maximum) was 64 (14-94) for patients described in both periods $(p=0.150)$.

\section{Medical attention required}

Most cases reported during the first period either required medical attention at the emergency room without hospital admission (99; $49.5 \%)$ or were in- 
hospital cases (99; 49.5\%). The two remaining cases (1\%) required hospital admission.

The number of cases requiring only medical attention at emergency room decreased during the second period (30; 4.8\%). In-hospital cases slightly decreased in relative terms although the absolute number of reports increased (277; 43.9\%). Conversely, cases requiring hospital admission increased both in relative and in absolute terms (236; 37.4\%). On the other hand, cases from outpatient department not requiring attention at the emergency room or hospital admission began to be reported during the second period, accounting for $13.9 \%$ (88) of the overall reports received at the end of this period ( $p<$ 0.001).

\section{Seriousness and outcome}

In the second period, the proportion of serious cases almost doubled $(63.1 \%$ vs $32.5 \%$ ) and the number of serious cases increased by more than 6-fold (398 vs 65; $p<0.001)$.

The most frequently reported outcome in both periods was recovery (70\% in the first one and $74.2 \%$ in the second one). The number of cases that recovered with sequelae was 2 in the first period and 16 in the second one. There were 9 fatal cases during the first period and 15 in the second one. The adverse reactions and drugs involved in these fatal cases are presented below in the drug-reaction associations section. Finally, the outcome was unknown in 49 cases in the first period and 132 in the second one $(p=0.153)$.

\section{$\underline{\text { Adverse reactions }}$}

Overall, 220 adverse reactions were described in the 200 first-period spontaneous reports. Cutaneous reactions were the most frequent, followed by cardiovascular and neurological reactions. In the 631 second-period 
spontaneous reports, 694 adverse reactions were described. Cutaneous reactions were the most frequent as well, followed in this case by haematological and gastrointestinal reactions (table 1). However, during the second period the frequency of endocrinological, urinary and hepatic reactions increased (3.7\% vs. $0.5 \%, 4.6 \%$ vs. $1.8 \%$ and $9.2 \%$ vs. $5.5 \%$, respectively).

The most commonly reported individual adverse reactions (with a frequency $\geq$ $3 \%$ of reports) during the first period were urticaria, angioedema, bronchospasm, hypotension, and haematoma. In the second period, individual reactions described in $\geq 3 \%$ of reports were rash and erythematous rash (table 2). During the second period the frequency of hyperthyroidism, thrombocytopenia and gastrointestinal haemorrhage increased by 4.3 and more than 2-fold, respectively.

\section{Suspected drugs}

Two hundred and eighty-five and 877 suspected pharmacological exposures were contained in the reports in the first and the second period respectively. In both periods, the most common therapeutic subgroups were systemic antibiotics, antithrombotics, and cardiac therapy. These three groups accounted for $38.2 \%$ and $30.3 \%$ of the total suspected pharmacological exposures in each period respectively (table 3 ). Regarding the remaining therapeutic subgroups, the greatest changes between periods were the increase in the proportion of immunostimulants, beta blocking agents, immunosuppressants and psychoanaleptics, and the decrease in the proportion of systemic antihistamines during the second period.

The drugs with the highest number of suspected exposures were amiodarone, amoxicillin-clavulanic acid, metamizole, and enoxaparin in both periods (table 4). Some drugs with no suspected exposures during the first period appeared during the second one (i.e., ceftriaxone, methotrexate, and tacrolimus). 
Additionally, a 9-fold increase was seen in the number of suspected exposures to ibuprofen, azithromycin and fluoxetine during the second period.

In both study periods, around $10 \%$ of suspected pharmacological exposures concerned recently marketed drugs. Nevertheless, both the overall number of suspected pharmacological exposures and the number of different drugs increased in the second period ( 97 vs. 28 , and 50 vs. 19 , respectively). The new drugs with the highest number of suspected exposures were clopidogrel, levofloxacin, and nevirapine (three exposures each) in the first period, and linezolid (eight exposures), tiotropium bromide, glatiramer acetate, oxcarbazepine, tenofovir, and voriconazole (five exposures each) in the second one.

\section{Drug-reaction associations}

In the first period, the most frequently reported drug-reaction associations were haemoperitoneum, retroperitoneal haemorrhage or muscular haematoma due to enoxaparin (11 cases, 5.5\% of reports). In the second period, they were hepatotoxicity induced by amoxicillin-clavulanic acid and hyperthyroidism due to amiodarone (14 cases and $2.2 \%$ of reports each) (table 5).

Three out of nine fatal reports from the first period were cases of haemorrhagic reactions in patients treated with enoxaparin (two retroperitoneal haemorrhages and a gastrointestinal bleeding), three were cases of cardiovascular reactions (myocardial infarction after terbutaline treatment, salbutamol and levofloxacin-induced torsade de pointes, and cardiac arrest in a patient treated with levomepromazine and carbamazepine) and the remaining three reports described adverse reactions related to other systems. The most frequent reactions in the fifteen fatal cases reported during the second period were also haemorrhagic events (seven cases). There were four cases of intracranial haemorrhage (three of them with tenecteplase, enoxaparin and acetylsalicylic acid, and one with drotrecogin alpha and enoxaparin), one case 
of enoxaparin-induced retroperitoneal haemorrhage, one case of intraabdominal haemorrhage due to enoxaparin, acenocoumarol and acetylsalicylic acid, and one case of acetylsalicylic acid-induced gastrointestinal haemorrhage. Of the eight remaining cases, three were toxic epidermal necrolysis and the other described reactions related to other systems.

\section{Previous knowledge/Signals identified}

The absolute number of previously unknown or poorly known drug-reaction associations had a fourfold increase in the second period (54 vs. 13 in the first period). Most of them were serious cases (5 out of 13 in the first period and 40 out of 54 in the second one; $p=0.047$ ).

No signals were identified during the first period. In the second one, two serious and previously unknown or poorly known drug-reaction associations were considered signals that required the adoption of regulatory measures by the Spanish Agency for Medicines and Medical Devices (AEMPS). The first signal was pseudoproteinuria induced by gelatine succinate infusion. A warning regarding this problem was added in the summary of product characteristics ${ }^{\text {[23] }}$ and a "Dear Dr letter" was sent to Spanish nephrologists and to the National Transplant Organization. The second signal was veralipride withdrawal syndrome; it required a risk-benefit assessment of the use of this orthopramide in the treatment of menopausal hot flushes and, as a result, the AEMPS withdrew this drug from the market. ${ }^{[24]}$ Afterwards, the EMEA also recommended the withdrawal of this drug from the European market. ${ }^{[25]}$

Additionally, the fatal case of cerebral haemorrhage due to drotrecogin alfa activated, which occurred in a patient who had recently undergone surgery, led to a review of safety data of this drug in the surgical population. As a result, the AEMPS proposed changes in the authorized conditions of use of drotrecogin alfa activated at the EMEA level. Those proposals contributed to updating the authorized conditions of use and contraindications of this drug. ${ }^{[26]}$ 


\section{DISCUSSION}

Our study has been the first one to assess the effect of a specific intervention on the features of ADRs spontaneously reported in a hospital setting, the drugs involved and the number of signals identified. It has shown that the improvement in spontaneous reporting of ADRs achieved following an intervention based on educational activities and economic incentives allowed us to detect some safety problems and to identify several signals. It is noteworthy that the reporting of all kind of adverse reactions and drugs increased.

The traditional methods and systems to detect ADRs in hospitals have been spontaneous reporting, intensive surveillance of hospital admissions and, more recently, computer-assisted approaches using routine data from hospital information systems. ${ }^{[3]}$ Different methods identify different types of ADRs and drugs. Moreover, the type of suspect drugs, their rank order and the types of ADRs identified vary widely among studies. In studies that only or predominantly included ADR-related hospitalisations, nonsteroidal antiinflammatory drugs causing gastrointestinal bleeding play a major role, followed by cardiovascular drugs and drugs acting on the central nervous system. In contrast, antibacterials/antiinfectives very often cause ADRs in hospitalised patients (mainly allergic reactions), as do opioids, cardiovascular drugs and

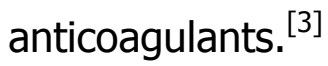

In our study the most frequently reported ADRs were similar in both periods, although some types of ADRs that were hardly reported on the first period increased in the second one. Cutaneous reactions were the most frequently reported ADRs in both periods: other ADRs commonly reported during both periods were cardiovascular, haematological, neurological and gastrointestinal reactions. Nevertheless, a high increase in endocrinological, urinary and hepatic 
reactions was observed in the second period. There are no other published studies comparing the effect of an intervention on the organ-system categories of reactions spontaneously reported in a hospital. A few studies have reported the pattern of spontaneously reported ADRs in hospitals. ${ }^{[16-19,27,28]}$ As in ours, in the majority of these studies dermatological reactions were the most frequently identified ${ }^{[17-19,27]}$ and skin rash was the most commonly reported reaction. ${ }^{[17,18]}$ Other ADRs such as neurological, gastrointestinal, and haematological reactions were also frequently reported. However, it is interesting to note that, in contrast with our study, endocrinological and urinary reactions were rarely reported in others. In our opinion, the intervention could be responsible for the increase in the reporting of these ADRs in the second period. Further studies should be carried out to analyze the effect of different interventions on the features of the spontaneously reported ADRs.

The majority of therapeutic subgroups of suspected drugs increased during the intervention. Systemic antibiotics, antithrombotics, and cardiac therapy drugs were the most commonly involved therapeutic subgroups in the spontaneous reports in both periods. These therapeutic subgroups were also frequently reported in other studies that assessed the drugs involved in spontaneously reported ADRs in hospitals. ${ }^{[18,19,27]}$ In our study, the greatest changes between periods were the increase in the proportion of immunostimulants, immunosuppressants and psychoanaleptics. In addition, antineoplastics, a therapeutic subgroup highly reported in other studies, ${ }^{[17,19,27]}$ also increased during the intervention. The therapeutic subgroups most commonly involved in the spontaneously reported ADRs were drugs frequently used in the hospital setting. Nevertheless, taking into account the differences in the pattern of suspect drugs in the two periods, it is likely that the intervention allowed us to identify during the second period some suspect drugs involved in ADRs infrequently reported in the first one. It would be interesting to investigate the effect of other interventions on the type of suspected drugs in spontaneously reported ADRs. 
Furthermore, the absolute number of spontaneous reports from any origin increased during the second period, except for those from emergencies. It is worth noting that spontaneous reports from the outpatient hospital consultations began to be reported during the second period. The effect of the intervention was evident, since the physicians had been informed in the educational meetings that they could report ADRs from every assistance setting. Unexpectedly, spontaneous reporting of ADRs requiring only medical attention at emergency room did not increase in spite of the intervention. The reason for that is unknown, although high attendance-pressure, specially in this area, lack of time, and other clinical priorities have been argued as potential obstacles to the spontaneous reporting of ADRs by the doctors at our hospital. ${ }^{[5]}$ Therefore, in the emergency area some other specific strategies aimed at increasing spontaneous reporting should be planned.

One of the main objectives of spontaneous reporting of ADRs is to detect drug safety concerns related to new drugs. Surprisingly, the novelty of suspect drugs has not been analyzed in published studies on spontaneous reporting in hospitals. In our study we observed that during the intervention the number of suspected pharmacological exposures to recently marketed drugs and the number of serious cases, including those with a fatal outcome, increased. It is noteworthy that one of the signals identified referred to a serious reaction to a recently marketed drug and arose through the reporting of a fatal case (i.e. intracranial haemorrhage associated to drotecogin alfa activated).

The majority of drug-reaction associations spontaneously reported in both periods of the study were well-known reactions related to old drugs (i.e., haemorrhage due to enoxaparin, hepatotoxicity due to amoxicillin-clavulanic acid, and hyperthyroidism due to amiodarone). However, the reporting of known ADRs can help to identify local problems related to the use of specific drugs. For example, in our hospital haemorrhages related to low-weight molecular heparins led to an analysis of the severe cases in order to identify possible risk factors. On the other hand, two previously unknown reactions 
associated with old drugs that were reported in the second period led to the withdrawal of the market of one drug and an update of the summary of product characteristics in the other one. This point is interesting because it shows that even old drugs must be kept under surveillance through their entire life-span to detect some possible previously unknown reactions.

Obviously our study has some limitations. First of all, it was carried out in only one hospital with specific characteristics (a teaching tertiary hospital; the biggest one in our geographical area). Additionally, the Catalan Centre of the Spanish Pharmacovigilance System is located in the hospital. Therefore, our findings could not be generalized to other hospitals. Secondly, since our study was a time series study without a control group, we can not rule out the influence of other factors in the observed results. Nevertheless, the number of the spontaneous ADRs reported by the other Catalan hospital to the Pharmacovigilance regional Centre during the two study's periods did not increase. Thirdly, the number of signals identified was low and we can not confirm the effect of intervention on its detection. Fourthly, we did not collect information on the category of physicians, medical speciality and other characteristics of the reporters that might have influenced the results. In spite of all these limitations, our study generates new information on the effect of a specific intervention on the features of the spontaneously reported ADRs, the drugs involved and the signals identified. On the one hand, that confirms the usefulness of the implementation of these types of strategies to improve reporting of ADRs in hospitals. On the other hand, these results can be and even should be used as an argument when stimulating the spontaneous reporting by health care professionals by means of supporting evidence of the usefulness of pharmacovigilance activities.

As a conclusion, an intervention based on educational activities and economic incentives led not only to a quantitative improvement in spontaneous reporting of ADRs by hospital physicians but also to a qualitative improvement in terms of seriousness of reactions identified affecting different organs or systems, and 


\section{Acknowledgments}

The authors would like to thank the hospital physicians who participated in this study for their collaboration. No sources of funding were used to assist in the development of this study. The authors have no conflicts of interest that are directly relevant to the content of this study. 


\section{References}

1. Wysowski DK, Swartz L. Adverse drug event surveillance and drug withdrawals in the United States, 1969-2002: the importance of reporting suspected reactions. Arch Intern Med 2005; 165: 1363-9

2. Aronson, JK. Adverse drug reactions - no farewell to harms. Br J Clin Pharmacol 2007; 63: 131-5

3. Thürmann PA. Methods and systems to detect adverse drug reactions in hospitals. Drug Safety 2001; 24: 961-8

4. Rawlins MD. Pharmacovigilance; paradise lost, regained or postponed?. The William Withering Lecture 1994. J R Coll Physicians Lond 1995; 29: 41-9

5. Vallano A, Cereza G, Pedros C, Agusti A, Danes I, Aguilera C, Arnau JM. Obstacles and solutions for spontaneous reporting of adverse drug reactions in the hospital. Br J Clin Pharmacol 2005; 60: 653-8

6. Moride Y, Haramburu F, Requejo AA, Begaud B. Under-reporting of adverse drug reactions in general practice. Br J Clin Pharmacol 1997; 43: 177-81

7. Figueiras A, Herdeiro MT, Polonia J, Gestal-Otero JJ. An educational intervention to improve physician reporting of adverse drug reactions: a clusterrandomized controlled trial. JAMA 2006; 296: 1086-93.

8. Nazario M, Feliu JF, Rivera GC. Adverse drug reactions: the San Juan Department of Veterans Affairs Medical Center experience. Hosp Pharm 1994; 29: $244-50$ 
9. Scott HD, Thacher-Renshaw A, Rosenbaum SE, Waters WJ Jr, Green M, Andrews LG, Faich GA. Physician reporting of adverse drug reactions. Results of the Rhode Island Adverse Drug Reaction Reporting Project. JAMA 1990; 263: $1785-8$

10. Fincham J. A statewide program to stimulate reporting of adverse drug reactions. J Pharm Pract 1989; 2: 239-44

11. McGettigan P, Golden J, Conroy RM, Arthur N, Feely J. Reporting of adverse drug reactions by hospital doctors and the response to intervention. $\mathrm{Br} \mathrm{J}$ Clin Pharmacol 1997; 44: 98-100

12. Kimelblatt BJ, Young SH, Heywood PM, Mandala AR, Gendelman S, Mehl B. Improved reporting of adverse drug reactions. Am J Hosp Pharm 1988; 45: 1086-9

13. Pedrós C, Vallano A, Cereza G, Mendoza-Aran G, Agustí A, Aguilera C, Danés I, Vidal $X$, Arnau JM. An intervention to improve spontaneous adverse drug reaction reporting by hospital physicians. A time series analysis in Spain. Drug Safety 2009; 32: 77-83

14. Maistrello I, Morgutti M, Maltempi M, Dantes M. Adverse drug reactions in hospitalized patients: an operational procedure to improve reporting and investigate underreporting. Pharmacoepidemiol Drug Saf 1995; 4: 101-6

15. Cox AR, Anton C, Goh CHF, Easter M, Langford NJ, Ferner RE. Adverse drug reactions in patients admitted to hospital identified by discharge ICD-10 codes and by spontaneous reports. $\mathrm{Br}$ J Clin Pharmacol 2001; 52: 337-9

16. Ortega A, Aguinagalde A, Lacasa C, Aquerreta I, Fernández-Benítez M, Fernández LM. Efficacy of an adverse drug reaction electronic reporting system 
integrated into a hospital information system. Ann Pharmacother 2008; 42: 1491-6

17. Jose J, Rao PGM. Pattern of adverse drug reactions notified by spontaneous reporting in an Indian tertiary care teaching hospital. Pharmacological Research 2006; 54: 226-33

18. Arulmani $R$, Rajendran SD, Suresh B. Adverse drug reaction monitoring in a secondary care hospital in South India. Br J Clin Pharmacol 2007; 65: 210-16

19. Baniasadi S, Fahimi F, Shalviri G. Developing an adverse drug reaction reporting system at a teaching hospital. Basic \& Clinical Pharmacology \& Toxicology 2008; 102: 408-11

20. Edwards R. Adverse drug reactions: finding the needle in the haystack. $\mathrm{Br}$ Med J 1997; 315: 500

21. Commission Directive 2000/38/EC of 5 June 2000 amending Chapter Va (Pharmacovigilance) of Council Directive 75/319/EEC on the approximation of provisions laid down by law, regulation or administrative action relating to medicinal products. Official Journal of the European Communities 10.6.2000: L139/28-L139/30 [online]. Available from URL: http://eurlex.europa.eu/LexUriServ/LexUriServ.do?uri=OJ:L:2000:139:0028:0030:EN:PDF [Accessed 2009 September 10]

22. Capellà D, Laporte J-R. La notificación espontánea de reacciones adversas a medicamentos. In: Laporte J-R, Tognoni G, editors. Principios de epidemiología del medicamento. $2^{\text {nd }}$ ed. Barcelona: Masson-Salvat, 1993: 147-70

23. Spanish Agency of Medicines and Health Products. Product Information. Gelafundina ${ }^{\circledR}$.

https://sinaem4.agemed.es/consaem/especialidad.do?metodo=verFichaWordPd 
$\underline{f \& \text { codigo }=61627 \& \text { formato }=p d f \& \text { formulario=FICHAS }}$ [Accessed 2009 September 10]

24. Spanish Agency of Medicines and Health Products. Informative note. Recommendations for the withdrawal of the treatment with Agreal ${ }^{\circledR}$ (Veralipride). http://www.agemed.es/actividad/alertas/docs/NI 200515 AGREAL.pdf [Accessed 2009 September 10]

25. European Medicines Agency. Questions and answers on the recommendation to withdraw the marketing authorisation of veralipride. http://www.emea.europa.eu/pdfs/human/referral/agreal/29946807en.pdf [Accessed 2009 September 10]

26. European Medicines Agency. Xigris. Procedural steps taken and scientific information after the authorisation. Changes made after 01/10/2004. http://www.emea.europa.eu/humandocs/PDFs/EPAR/xigris/H-396-en8b.pdf [Accessed 2009 September 10]

27. Uppal R, Jhaj R, Malhotra S. Adverse drug reactions among inpatients in a north Indian referral hospital. Natl Med J India 2000; 13: 16-8

28. Lugardon S, Desboeuf K, Fernet $P$, Monstastruc J-L, Lapeyre-Mestre M. Using a capture-recapture method to assess the frequency of adverse drug reactions in a French university hospital. Br J Clin Pharmacol 2006; 62: 225-31 
Table 1. Adverse drug reactions classified by organ or system affected

\begin{tabular}{lcccc}
\hline \multicolumn{1}{c}{ Organ or system } & \multicolumn{2}{c}{ First period } & \multicolumn{2}{c}{ Second period } \\
& $\mathrm{N}$ & $(\%)$ & $\mathrm{N}$ & $(\%)$ \\
\hline Cutaneous reactions & 44 & $(20.0)$ & 128 & $(18.4)$ \\
Haematological reactions & 23 & $(10.5)$ & 68 & $(9.8)$ \\
Gastrointestinal reactions & 19 & $(8.6)$ & 68 & $(9.8)$ \\
Cardiovascular reactions & 27 & $(12.3)$ & 67 & $(9.7)$ \\
Hepatic reactions & 12 & $(5.5)$ & 64 & $(9.2)$ \\
Neurological reactions & 26 & $(11.8)$ & 58 & $(8.4)$ \\
Metabolic and nutritional reactions & 10 & $(4.5)$ & 43 & $(6.2)$ \\
Respiratory reactions & 19 & $(8.6)$ & 39 & $(5.6)$ \\
General disorders & 9 & $(4.1)$ & 37 & $(5.3)$ \\
Urinary reactions & 4 & $(1.8)$ & 32 & $(4.6)$ \\
Endocrinological reactions & 1 & $(0.5)$ & 26 & $(3.7)$ \\
Psychiatric reactions & 12 & $(5.5)$ & 24 & $(3.5)$ \\
Others & 14 & $(6.3)$ & 40 & $(5.8)$ \\
\hline Total & 220 & $(100)$ & 694 & $(100)$ \\
\hline
\end{tabular}


1

Table 2. Most frequent adverse reactions

\begin{tabular}{|c|c|c|c|c|}
\hline \multirow[t]{2}{*}{ Adverse reaction } & \multicolumn{2}{|c|}{$\begin{array}{l}\text { First period } \\
(\mathrm{N}=220)\end{array}$} & \multicolumn{2}{|c|}{$\begin{array}{l}\text { Second period } \\
\qquad(N=694)\end{array}$} \\
\hline & $\mathrm{N}$ & $(\%)$ & $\mathrm{N}$ & $(\%)$ \\
\hline Erythematous rash & 5 & $(2.3)$ & 31 & $(4.5)$ \\
\hline Rash & 6 & $(2.7)$ & 25 & $(3.6)$ \\
\hline Hepatitis & 3 & (1.4) & 20 & $(2.9)$ \\
\hline Thrombocytopenia & 2 & $(0.9)$ & 19 & $(2.7)$ \\
\hline Hepatic enzymes increased & 6 & $(2.7)$ & 18 & $(2.6)$ \\
\hline Acute renal failure & 4 & $(1.8)$ & 18 & $(2.6)$ \\
\hline Hepatitis cholestatic & 3 & $(1.4)$ & 17 & $(2.4)$ \\
\hline Gastrointestinal haemorrhage & 2 & $(0.9)$ & 17 & $(2.4)$ \\
\hline Diarrhoea & 3 & (1.4) & 16 & $(2.3)$ \\
\hline Anaphylactic shock & 4 & $(1.8)$ & 15 & $(2.2)$ \\
\hline Heart failure & 2 & $(0.9)$ & 14 & $(2.0)$ \\
\hline Hyperthyroidism & 1 & $(0.5)$ & 14 & $(2.0)$ \\
\hline Urticaria & 10 & $(4.5)$ & 12 & $(1.7)$ \\
\hline Angioedema & 9 & $(4.1)$ & 11 & $(1.6)$ \\
\hline Bronchospasm & 9 & $(4.1)$ & 10 & $(1.4)$ \\
\hline Haematoma & 8 & (3.6) & 9 & $(1.3)$ \\
\hline Atrioventricular block & 4 & $(1.8)$ & 8 & $(1.2)$ \\
\hline Encephalopathy & 4 & $(1.8)$ & 8 & $(1.2)$ \\
\hline Extrapiramidal disorder & 5 & $(2.3)$ & 4 & $(0.6)$ \\
\hline Retroperitoneal haemorrhage & 6 & $(2.7)$ & 3 & $(0.4)$ \\
\hline Distonia & 5 & $(2.3)$ & 3 & $(0.4)$ \\
\hline Hypotension & 9 & $(4.1)$ & 2 & $(0.3)$ \\
\hline
\end{tabular}

Only adverse reactions present in at least five reports of any period are displayed. 
Table 3. Suspect drugs by therapeutic subgroup

\begin{tabular}{lcccc}
\hline \multirow{2}{*}{ Therapeutic subgroup } & \multicolumn{2}{c}{ First period } & \multicolumn{2}{c}{ Second period } \\
\cline { 2 - 5 } & $\mathrm{N}$ & $(\%)$ & $\mathrm{N}$ & $\%$ \\
\hline Systemic antibiotics (J01) & 62 & $(21.8)$ & 149 & $(17.0)$ \\
Antithrombotics (B01) & 30 & $(10.5)$ & 69 & $(7.9)$ \\
Cardiac therapy (C01) & 17 & $(6.0)$ & 47 & $(5.4)$ \\
Antiinflammatories and antirheumatics (M01) & 12 & $(4.2)$ & 46 & $(5.2)$ \\
Psychoanaleptics (N06) & 8 & $(2.8)$ & 44 & $(5.0)$ \\
Analgesics (N02) & 17 & $(6.0)$ & 35 & $(4.0)$ \\
Drugs acting on the renin-angiotensin system (C09) & 10 & $(3.5)$ & 35 & $(4.0)$ \\
Antiepileptics (N03) & 9 & $(3.1)$ & 35 & $(4.0)$ \\
Antineoplastics (L01) & 8 & $(2.8)$ & 34 & $(3.9)$ \\
Antimycobacterials (J04) & 14 & $(4.9)$ & 32 & $(3.6)$ \\
Systemic antivirals (J05) & 7 & $(2.5)$ & 31 & $(3.5)$ \\
Immunosuppressive drugs (L04) & 4 & $(1.4)$ & 29 & $(3.3)$ \\
Diuretics (C03) & 9 & $(3.1)$ & 27 & $(3.1)$ \\
Psycholeptics (N05) & 9 & $(3.1)$ & 24 & $(2.7)$ \\
Drugs for obstructive airway diseases (R03) & 6 & $(2.1)$ & 22 & $(2.5)$ \\
Beta blocking drugs (C07) & 3 & $(1.1)$ & 22 & $(2.5)$ \\
Immunostimulants (L03) & 0 & $(-)$ & 18 & $(2.1)$ \\
Systemic corticosteroids (H02) & 4 & $(1.4)$ & 16 & $(1.8)$ \\
Lipid modifying drugs (C10) & 6 & $(2.1)$ & 15 & $(1.7)$ \\
Systemic antihistamines (R06) & 11 & $(3.9)$ & 4 & $(0.5)$ \\
Others & 39 & $(13.7)$ & 143 & $(16.3)$ \\
\hline Total & 285 & $(100)$ & 877 & $(100)$ \\
\hline
\end{tabular}


Table 4. Most frequent suspect drugs

\begin{tabular}{|c|c|c|c|c|c|c|}
\hline \multirow{3}{*}{ Drug } & \multicolumn{3}{|c|}{ First period } & \multicolumn{3}{|c|}{ Second period } \\
\hline & \multicolumn{2}{|c|}{$\begin{array}{l}\text { Suspect exposures } \\
\qquad(\mathrm{N}=285)\end{array}$} & \multirow{2}{*}{$\begin{array}{c}\begin{array}{c}\text { Reports } \\
(\mathrm{N}=200)\end{array} \\
\%\end{array}$} & \multicolumn{2}{|c|}{$\begin{array}{l}\text { Suspect exposures } \\
\qquad(\mathrm{N}=877)\end{array}$} & \multirow{2}{*}{$\begin{array}{c}\begin{array}{c}\text { Reports } \\
(\mathrm{N}=631)\end{array} \\
\%\end{array}$} \\
\hline & $\mathrm{N}$ & $(\%)$ & & $\mathrm{N}$ & $(\%)$ & \\
\hline Amiodarone & 11 & (3.9) & 5.5 & 36 & $(4.1)$ & 5.7 \\
\hline Amoxicillin-clavulanic acid & 16 & $(5.6)$ & 8.0 & 35 & (3.9) & 5.5 \\
\hline Metamizole & 12 & $(4.2)$ & 6.0 & 23 & $(2.6)$ & 3.6 \\
\hline Enoxaparin & 16 & $(5.6)$ & 8.0 & 21 & $(2.4)$ & 3.3 \\
\hline Enalapril & 4 & $(1.4)$ & 2.0 & 21 & $(2.4)$ & 3.3 \\
\hline Ibuprofen & 2 & $(0.7)$ & 1.0 & 18 & $(2.1)$ & 2.9 \\
\hline Acenocoumarol & 2 & $(0.7)$ & 1.0 & 15 & $(1.7)$ & 2.4 \\
\hline Acetylsalicylic acid & 6 & $(2.1)$ & 3.0 & 14 & $(1.6)$ & 2.2 \\
\hline Prednisone & 2 & $(0.7)$ & 1.0 & 13 & $(1.5)$ & 2.1 \\
\hline Phenytoin & 3 & $(1.1)$ & 1.5 & 10 & $(1.1)$ & 1.6 \\
\hline Levofloxacin & 3 & $(1.1)$ & 1.5 & 10 & (1.1) & 1.6 \\
\hline Pyrazinamide & 3 & $(1.1)$ & 1.5 & 10 & (1.1) & 1.6 \\
\hline Furosemide & 3 & $(1.1)$ & 1.5 & 9 & $(1.0)$ & 1.4 \\
\hline Azithromycin & 1 & $(0.4)$ & 0.5 & 9 & $(1.0)$ & 1.4 \\
\hline Fluoxetine & 1 & $(0.4)$ & 0.5 & 9 & $(1.0)$ & 1.4 \\
\hline Ciprofloxacin & 6 & $(2.1)$ & 3.0 & 8 & $(0.9)$ & 1.3 \\
\hline Spironolactone & 1 & $(0.4)$ & 0.5 & 8 & $(0.9)$ & 1.3 \\
\hline Linezolid & 0 & $(-)$ & - & 8 & $(0.9)$ & 1.3 \\
\hline Diclofenac & 6 & $(2.1)$ & 3.0 & 7 & $(0.8)$ & 1.1 \\
\hline Hydrochlorothiazide & 3 & $(1.1)$ & 1.5 & 7 & $(0.8)$ & 1.1 \\
\hline Cefepime & 2 & $(0.7)$ & 1.0 & 7 & $(0.8)$ & 1.1 \\
\hline Rifampicin-isoniazid & 1 & $(0.4)$ & 0.5 & 7 & $(0.8)$ & 1.1 \\
\hline Clarithromycin & 5 & $(1.8)$ & 2.5 & 6 & $(0.7)$ & 1.0 \\
\hline Carbamazepine & 3 & $(1.1)$ & 1.5 & 6 & $(0.7)$ & 1.0 \\
\hline Digoxin & 3 & $(1.1)$ & 1.5 & 6 & $(0.7)$ & 1.0 \\
\hline Moxifloxacin & 2 & $(0.7)$ & 1.0 & 6 & $(0.7)$ & 1.0 \\
\hline Azathioprine & 1 & $(0.4)$ & 0.5 & 6 & $(0.7)$ & 1.0 \\
\hline Vancomycin & 1 & $(0.4)$ & 0.5 & 6 & $(0.7)$ & 1.0 \\
\hline Ceftriaxone & 0 & $(-)$ & - & 6 & $(0.7)$ & 1.0 \\
\hline Methotrexate & 0 & $(-)$ & - & 6 & $(0.7)$ & 1.0 \\
\hline Tacrolimus & 0 & $(-)$ & - & 6 & $(0.7)$ & 1.0 \\
\hline Thiethylperazine & 8 & $(2.8)$ & 4.0 & 3 & $(0.3)$ & 0.5 \\
\hline
\end{tabular}

Only drugs with at least six suspect exposures in any period are displayed. 
Table 5. Most frequent drug-reaction associations

\begin{tabular}{|c|c|c|c|c|c|}
\hline \multirow[t]{2}{*}{ Drug } & \multirow[t]{2}{*}{ Reaction } & \multicolumn{2}{|c|}{$\begin{array}{c}\text { First period } \\
(\mathrm{N}=200 \text { reports })\end{array}$} & \multicolumn{2}{|c|}{$\begin{array}{l}\text { Second period } \\
\text { (N=631 reports) }\end{array}$} \\
\hline & & $\mathrm{N}$ & $(\%)$ & $\mathrm{N}$ & $(\%)$ \\
\hline Amoxicillin-clavulanic acid & Hepatic enzymes increased, hepatitis or cholestatic hepatitis & 2 & $(1.0)$ & 14 & $(2.2)$ \\
\hline Amiodarone & Hyperthyroidism & 1 & $(0.5)$ & 14 & $(2.2)$ \\
\hline Enoxaparin & Haemoperitoneum, retroperitoneal haemorrhage or haematoma & 11 & $(5.5)$ & $8^{\mathrm{a}}$ & $(1.3)$ \\
\hline Acenocoumarol & Haemoperitoneum, retroperitoneal haemorrhage or haematoma & 1 & $(0.5)$ & $7^{\mathrm{a}}$ & $(1.1)$ \\
\hline Amiodarone & QT interval prolonged, torsade de pointes or ventricular fibrillation & 0 & $(-)$ & 7 & $(1.1)$ \\
\hline Phenytoin & Erythematous, maculopapular or unspecified rash & 1 & $(0.5)$ & 7 & $(1.1)$ \\
\hline Metamizole & Erythematous, maculopapular or unspecified rash & 1 & $(0.5)$ & 7 & $(1.1)$ \\
\hline Enalapril & Acute renal failure & 0 & $(-)$ & 6 & $(1.0)$ \\
\hline Prednisone & Hyperglycaemia, diabetes mellitus or diabetes mellitus aggravated & 0 & $(-)$ & 6 & $(1.0)$ \\
\hline Acetylsalicylic acid & Gastrointestinal haemorrhage & $1^{\mathrm{b}}$ & $(0.5)$ & $5^{c}$ & $(0.8)$ \\
\hline Enalapril & Cough & 0 & $(-)$ & 5 & $(0.8)$ \\
\hline Enoxaparin & Cerebral haemorrhage & 0 & $(-)$ & $5^{d}$ & $(0.8)$ \\
\hline Thiethylperazine & Distonia and/or dyskinesia & 7 & (3.5) & 3 & $(0.5)$ \\
\hline Amoxicillin-clavulanic acid & Angioedema or laryngeal oedema & 5 & $(2.5)$ & 0 & $(-)$ \\
\hline
\end{tabular}

Only associations present in at least five reports of any period are displayed.

a Concomitant administration of enoxaparin and acenocoumarol in two cases. ${ }^{b}$ Enoxaparin concomitantly administered. ' Drugs concomitantly administered: clopidogrel (in one case); clopidogrel, enoxaparin and abciximab (in one case); enoxaparin and streptokinase (in one case). ${ }^{\mathrm{d}}$ Drugs concomitantly administered: tenecteplase and acetylsalicylic acid (in four cases); drotrecogin alfa activated (in one case). 
